\title{
The effect of transdermal scopolamine for the prevention of postoperative nausea and vomiting
}

\author{
María A. Antor ${ }^{1}$, Alberto A. Uribe ${ }^{2}{ }^{*}$, Natali Erminy-Falcon $^{3}$, Joseph G. Werner ${ }^{2}$, Keith A. Candiotti ${ }^{1}$, \\ Joseph V. Pergolizzi ${ }^{4}$ and Sergio D. Bergese ${ }^{2,5}$
}

' Department of Anesthesiology, Perioperative Medicine and Pain Management, Jackson Memorial Hospital, Miami, FL, USA

2 Department of Anesthesiology, The Ohio State University Werner Medical Center, Columbus, OH, USA

${ }^{3}$ Department of Internal Medicine, Riverside Methodist Hospital, Columbus, OH, USA

${ }^{4}$ Department of Medicine, The Johns Hopkins University School of Medicine, Baltimore, MD, USA

${ }^{5}$ Department of Neurological Surgery, The Ohio State University Medical Center, Columbus, OH, USA

\section{Edited by:}

Suren Soghomonyan, The Ohio State University Wexner Medical Center, USA

\section{Reviewed by:}

Suren Soghomonyan, The Ohio State University Wexner Medical Center. USA

Nicoleta Stoicea, Ohio State University Wexner Medical CenterCollege of Medicine, USA

\section{*Correspondence:}

Alberto A. Uribe, Department of Anesthesiology, The Ohio State University Werner Medical Center, 410 West 10th Avenue, N411 Doan Hall, Columbus, OH 43210, USA e-mail: alberto.uribe@osumc.edu
Postoperative nausea and vomiting (PONV) is one of the most common and undesirable complaints recorded in as many as $70-80 \%$ of high-risk surgical patients. The current prophylactic therapy recommendations for PONV management stated in the Society of Ambulatory Anesthesia (SAMBA) guidelines should start with monotherapy and patients at moderate to high risk, a combination of antiemetic medication should be considered. Consequently, if rescue medication is required, the antiemetic drug chosen should be from a different therapeutic class and administration mode than the drug used for prophylaxis. The guidelines restrict the use of dexamethasone, transdermal scopolamine, aprepitant, and palonosetron as rescue medication $6 \mathrm{~h}$ after surgery. In an effort to find a safer and reliable therapy for PONV, new drugs with antiemetic properties and minimal side effects are needed, and scopolamine may be considered an effective alternative. Scopolamine is a belladonna alkaloid, $\alpha$-(hydroxymethyl) benzene acetic acid 9-methyl3-oxa-9-azatricyclo non-7-yl ester, acting as a non-selective muscarinic antagonist and producing both peripheral antimuscarinic and central sedative, antiemetic, and amnestic effects. The empirical formula is $\mathrm{C}_{17} \mathrm{H}_{21} \mathrm{NO}_{4}$ and its structural formula is a tertiary amine L-(2)-scopolamine (tropic acid ester with scopine; $M W=303.4$ ). Scopolamine became the first drug commercially available as a transdermal therapeutic system used for extended continuous drug delivery during $72 \mathrm{~h}$. Clinical trials with transdermal scopolamine have consistently demonstrated its safety and efficacy in PONV. Thus, scopolamine is a promising candidate for the management of PONV in adults as a first line monotherapy or in combination with other drugs. In addition, transdermal scopolamine might be helpful in preventing postoperative discharge nausea and vomiting owing to its long-lasting clinical effects.

Keywords: nausea, vomiting, antiemetic, postoperative, prophylaxis, transdermal scopolamine, pharmacokinetics, pharmacodynamics

\section{INTRODUCTION}

Postoperative nausea and vomiting (PONV) are among the most common complaints from patients and clinicians (Jones et al., 2006; Sood etal., 2007). Prevention and treatment of PONV is a key patient care component capable of alleviating patient discomfort, distress, and dissatisfaction during the postoperative period. PONV per se is a significant complication that may lead to other postoperative adverse events including aspiration, pneumonitis, dehydration, wound dehiscence, acid-base disorders, and electrolyte imbalance, hematoma formation, esophageal rupture, increases in intraocular and/or intracranial pressures, and acute blood pressure elevations (Fabling et al., 2000; Lipp and Kaliappan, 2007; Feng et al., 2009). According to Society of Ambulatory Anesthesia (SAMBA) Consensus Guidelines for the Management of PONV, the incidence of PONV is between 20 $30 \%$ among all patients undergoing surgery. With no prophylactic therapy, PONV occurs in as many as $70-80 \%$ of high-risk patients undergoing surgery (Gan et al., 2014). Three categories of baseline risk factors: patient-specific, anesthetic, and surgical, are independent predictors of PONV, and may be helpful in selecting the right candidates for prophylaxis. The most prevalent patient and anesthesia related risk factors for PONV are female gender, nonsmoking status, postoperative opioid consumption, and a history of PONV/postoperative discharge nausea and vomiting (PDNV) or motion sickness (Apfel et al., 1999). Each factor has a punctuation value of 1 , which, when added, will equal $0-4$. When 0 , $1,2,3$, or 4 of the above mentioned independent predictors are present; the corresponding risk for PONV is approximately 10 , $20,40,60$, or $80 \%$, respectively (Gan and Habib, 2003; Gan et al., 2014). Presence of a single risk factor corresponds to a $20 \%$ risk of PONV, while combination of all the risk factors will be related to an $80 \%$ chance of PONV (Apfel et al., 1999). The SAMBA Consensus Guidelines for the Management of PONV include assessing the patient's risk, reducing the baseline risk factors, and providing 
prophylactic treatment. The current (Gan et al., 2014) prophylactic therapy recommendations for PONV management stated in the SAMBA guidelines should start with monotherapy and patients at moderate to high risk, a combination of antiemetic medication should be considered. Consequently, if rescue medication is required, the antiemetic drug chosen should be from a different therapeutic class and administration mode than the drug used for prophylaxis. Considering the increasing rate of outpatient surgeries, long-lasting prophylactic antiemetic therapeutic efforts may be beneficial for postoperative patient care and improve the outcomes. Scopolamine is a long-acting prophylactic antiemetic (72 h) approved in 1979 by the Food and Drug Administration (FDA; Apfel et al., 2010) as a method of preventing motion sickness and, since 2001 - for prevention of PONV. In outpatient surgical patients, PDNV usually remains unrecorded because of early discharge, despite the fact that the patients report this complication as the most undesirable postoperative event. Thus, taking into account the beneficial effects of scopolamine, its favorable pharmacokinetic and pharmacodynamic profile, and importance of PONV prophylaxis, transdermal delivery system (TDS) may become a strong candidate as a first-line prophylactic medication in perioperative care (Pergolizzi et al., 2012).

\section{OVERVIEW OF SCOPOLAMINE}

Scopolamine is a non-polar, belladonna alkaloid, $\alpha$ (hydroxymethyl) benzeneacetic acid 9-methyl-3-oxa-9-azatricyclo non-7-yl ester. The empirical formula is $\mathrm{C}_{17} \mathrm{H}_{21} \mathrm{NO}_{4}$ and its structural formula is a tertiary amine $\mathrm{L}-(2)$-scopolamine. It is a viscous liquid that has a molecular weight of 303.35 and a pKa of 7.55-7.81. Scopolamine is a high-affinity selective competitive antagonist of $\mathrm{G}$ protein-coupled muscarinic receptor for acetylcholine with both, peripheral and central antimuscarinic effects, including sedative, antiemetic, and amnesic action (Pergolizzi et al., 2011). It acts on the central nervous system (CNS) by blocking cholinergic transmission from vestibular nuclei to higher CNS centers and from the reticular formation to the vomiting center (Renner et al., 2005; Package Insert, 2006). Scopolamine is available as an oral tablet, injectable solution, and TDS. However, the oral and/or parenteral routes of administration are rarely used due to pronounced dose-dependent side effects (excessive sedation, agitation, hallucinations, vertigo, dry mouth, and drowsiness) and a short plasma half-life.

\section{TRANSDERMAL SCOPOLAMINE: PHARMACOKINETICS AND PHARMACODYNAMIC PROPERTIES}

Transdermal delivery system (TDS) delivery system (patch) functions as a long-acting prophylactic antiemetic $(72 \mathrm{~h})$. It is a $0.2 \mathrm{~mm}$ thick and $2.5 \mathrm{~cm}^{2}$ film, with four layers (Pergolizzi et al., 2012). The first layer of the patch is a tancolored aluminized polyester film. The second layer is a drug reservoir mixture of scopolamine, light mineral oil, and polyisobutylene. The third layer represents a dose delivery rate controlling microporous polypropylene membrane, and the fourth layer is an adhesive surface formulation of mineral oil, polyisobutylene, and priming dose of scopolamine applied directly to the skin (Nachum et al., 2006; Package Insert, 2006). Only the active drug scopolamine is being released from the delivery system during the TDS application. This patch is designed for continuous release of scopolamine following application to the skin, with the highest permeation rate in the postauricular (mastoid) area, and the lowest permeation in the thigh, higher in the forearm, and still higher in the stomach, chest and back (Pergolizzi et al., 2011).

The TDS contains $1.5 \mathrm{mg}$ of the drug in a reservoir designed to provide a continuous slow release of scopolamine through intact skin during the first $72 \mathrm{~h}$ of patch application (Pergolizzi et al., 2011). The priming dose of scopolamine (140 $\mu \mathrm{g})$, when applied to the post-auricular area, increases the plasma detectable levels are reached within $4 \mathrm{~h}$ with a peak level at $24 \mathrm{~h}$. The rate of scopolamine release after the patch application equals $0.5 \mathrm{mg} /$ day of scopolamine over a 3 days period. The average plasma concentration produced is $87 \mathrm{pg} / \mathrm{mL}$ for free scopolamine and $354 \mathrm{pg} / \mathrm{mL}$ for total scopolamine (free fraction and conjugated drug; Package Insert, 2006). After removal of the used system, plasma scopolamine levels decrease gradually with an elimination half-life of $9.5 \mathrm{~h}$ (Pergolizzi et al., 2011). Upon absorption, scopolamine is mostly bound to plasma proteins and undergoes an almost complete hepatic elimination via hepatic conjugation with subsequent urinary excretion of hydrophilic metabolites. Less than $5 \%$ of scopolamine is excreted unchanged (Renner et al., 2005; Nachum etal., 2006). Like atropine, scopolamine acts as a non-specific competitive antagonist of acetylcholine at muscarinic receptors. Due to receptor sensitivity, the inhibition of salivation (M3 receptors) can be reached at lower doses, whereas much higher doses are needed to induce cardiac effects (M2 receptors). As a result, the measured plasma scopolamine concentration does not necessarily correlate with the extent of pharmacodynamic effects of the drug. Scopolamine pharmacodynamics only quantitatively differs from that of atropine. Whereas atropine has almost no detectable effects on CNS in clinically applicable doses, scopolamine exerts prominent CNS effects at low therapeutic doses. This difference may be explained by a better penetration of scopolamine through the blood brain barrier. Adverse effects associated with the use of scopolamine can, in the majority of cases, be attributed to an extension of its pharmacodynamic effects, and result from excessive anticholinergic activity (Renner et al., 2005; Nachum et al., 2006).

The commonest side effects reported for scopolamine therapy are sedation, dry mouth, blurry vision, central cholinergic syndrome, and confusion (Apfel et al., 2010). Scopolamine produces mydriasis and cycloplegia by paralyzing the sphincter muscle of the iris and the ciliary muscle of the lens. These effects on eye may last up to 7-12 days after a topical application of scopolamine. Although, systematically administered scopolamine has little effect on the intraocular pressure, patients with narrow-angle glaucoma may develop dangerous increases in the intraocular pressure following scopolamine (Renner et al., 2005). Additional side effects include reduction of gastric secretions and salivation, decreases in smooth muscle tone in the gastrointestinal tract, leading to a hypomotility, dryness of the nasopharynx, mouth, bronchi, and bronchioli. Following smooth muscle relaxation after scopolamine administration, the airway resistance in the respiratory tract is reduced. The drug exerts a similar relaxing effect on the smooth muscle tone of urethra and bladder (Renner et al., 2005). 


\section{CLINICAL EFFICACY}

Transdermal delivery system patches have proved to be highly effective in the management of motion sickness and PONV. This is also supported by experimental data and studies on human volunteers, showing a higher efficacy of TDS compared to placebo (Table 1; Graybiel, 1979; Graybiel et al., 1981, 1982; Dahl et al., 1984; Shojaku et al., 1993). Kotelko et al. (1989) studied patients undergoing elective cesarean delivery under epidural anesthesia with the addition of epidural morphine for postoperative analgesia. They reported a significant reduction in nausea, vomiting, and retching when comparing the TDS group vs. placebo during the study period of $2-10 \mathrm{~h}$ after surgery. Additionally, the TDS group required less antiemetic medication during the first 24 postoperative hours. The adverse effects experienced by the patients in both groups were dizziness $(8 \%)$, blurred vision $(4 \%$ in TDS group vs. $2 \%$ placebo group) and disorientation (1\% TDS group vs. none in the placebo group). As it was shown, side effects were minimal in both groups (Kotelko et al., 1989). Harnett et al. (2007) carried out a similar study in women undergoing cesarean delivery under spinal anesthesia and induced opioid analgesia to compare the effects of TDS, placebo, and ondansetron on PONV. They administered antiemetic prophylaxis after clamping the umbilical cord instead of applying the TDS before surgery as Kotelko et al. (1989) reported. This relevant difference should be considered in order to avoid potential exposure of the fetus and consequent side effects. Their results showed that TDS was significantly superior to ondansetron or placebo as a PONV prophylactic therapy. The overall postoperative emesis rate was $59.3 \%$ in the placebo group and was reduced to $40 \%$ in the scopolamine group and $41.8 \%$ in the ondansetron group, respectively. The authors evaluated the effects of aforementioned drugs at different time periods postoperatively $(0-2 \mathrm{~h}, 2-6 \mathrm{~h}$, and $6-24 \mathrm{~h})$, and it was concluded that the efficacy of scopolamine was higher compared to ondansetron or placebo during the postoperative 6-24 h interval. The side effects reported during the study did not lead to discontinuation of drug use in any patient. Dizziness varied significantly among the groups, but the relative incidence was not consistent across the time intervals. Dry mouth was somewhat more common in the scopolamine group in the 6-24 h interval (9\% in placebo group, $4 \%$ in ondansetron group, $19 \%$ in scopolamine group). Similarly, blurry vision was more common in the scopolamine group than placebo at 6-24 h (6\% vs. 0\%). Lethargy occurred in $<10 \%$ of subjects during all time intervals, and its frequency did not differ among the groups. The differences in drug effects at different time periods may be related to the pharmacokinetic and pharmacodynamic properties of the drug (Harnett et al., 2007).

Einarsson et al. (2008) concluded that the TDS significantly reduces the incidence and severity of nausea and vomiting in the first $24 \mathrm{~h}$ after gynecologic laparoscopic surgery. They found a significantly higher rate of visual disturbances compared with the placebo group $(45.8 \%$ vs. $8.3 \%)$. Symptoms of dry mouth were also slightly more common in the scopolamine group, but generally did not seem to be bothersome to study participants (87.5\% vs. $79.2 \%$; Einarsson et al., 2008). Jones et al. (2006) compared the efficacy of active TDS plus ondansetron with a placebo patch plus ondansetron in high-risk patients scheduled to receive a short duration general anesthesia for no longer than an hour. They found that patients receiving a combination of TDS and ondansetron reported fewer incidences $(39 \%)$ of PONV compared to those who received ondansetron alone (75\%). The most frequently reported side effect was headache, which has been attributed to ondansetron (Jones et al., 2006). White et al. (2007) compared a combination of TDS with droperidol vs. TDS with ondansetron in patient undergoing major laparoscopic surgeries, the study showed that both combinations were equally effective in preventing nausea and vomiting during the first $72 \mathrm{~h}$ of the post-operative period with a complete response of 41 and 51\%, respectively (White et al., 2007).

Recently, a study by Sah et al. (2009) showed the efficacy of TDS plus ondansetron vs. placebo patch plus ondansetron on the incidence of PONV in 126 patients undergoing plastic surgery. A statistically significant reduction in postoperative nausea between 8 and $24 \mathrm{~h}$ in patients who received TDS was observed. During the first $4 \mathrm{~h}$, no significant difference between the two groups was revealed, which may be attributed to ondansetron administration in both groups. The most common side effect was dry mouth in $70 \%$ of patients in the transdermal group compared with $63 \%$ in the placebo group. Visual disturbance was found in $15 \%$ of the TD group compared to $5 \%$ of patients in the placebo group. Sedation was common and notable in $40 \%$ of TD group vs. $33 \%$ of the placebo group, probably related to postoperative opioid use (Sah et al., 2009). Gan et al. (2009) confirmed the previous findings; they expanded the time of observed effectiveness of TDS with data collected from $0-48 \mathrm{~h}$ postoperatively and included the largest sample size to date. The study examined active TDS plus ondansetron compared with placebo patch plus ondansetron as a prophylactic treatment for PONV in 620 female patients undergoing outpatient laparoscopic or breast augmentation surgery. This study found a significant reduction in PONV incidence $24 \mathrm{~h}$ after surgery in the group receiving TDS plus ondansetron compared to the reference group that received placebo patch plus ondansetron. Despite the fact that TDS has a slow onset of action, this study showed that the clinical benefits are apparent when TDS is administered in combination with ondansetron $2 \mathrm{~h}$ before induction of anesthesia. In addition, this trial observed that the overall incidence of adverse events was less frequent in the group receiving TDS in combination with ondansetron compared with the group receiving ondansetron alone (36.7\% vs. 49\%; Gan et al., 2009). The combined use of TDS and dexamethasone by Lee et al. (2010a) showed that patients undergoing major orthopedic surgery using patientcontrolled analgesia (PCA) was more effective in preventing PONV compared with dexamethasone alone or dexamethasone plus ramosetron $(47.5 \%$ vs. $82.5 \%$ and $50.0 \%$, respectively; Lee et al., 2010a). Limitations of this study include the lack of a control group without prophylaxis, the $24 \mathrm{~h}$ limits of patient evaluation after surgery, inability to evaluate the drug's effects on the urinary function because of the presence of an indwelling urinary catheter (Lee et al., 2010a). Lee et al. (2010a) designed a similar randomized controlled trial that evaluated the efficacy of preventing nausea using TDS with ondansetron vs. ondansetron alone after uterine artery embolization (UAE). The overall incidence of 


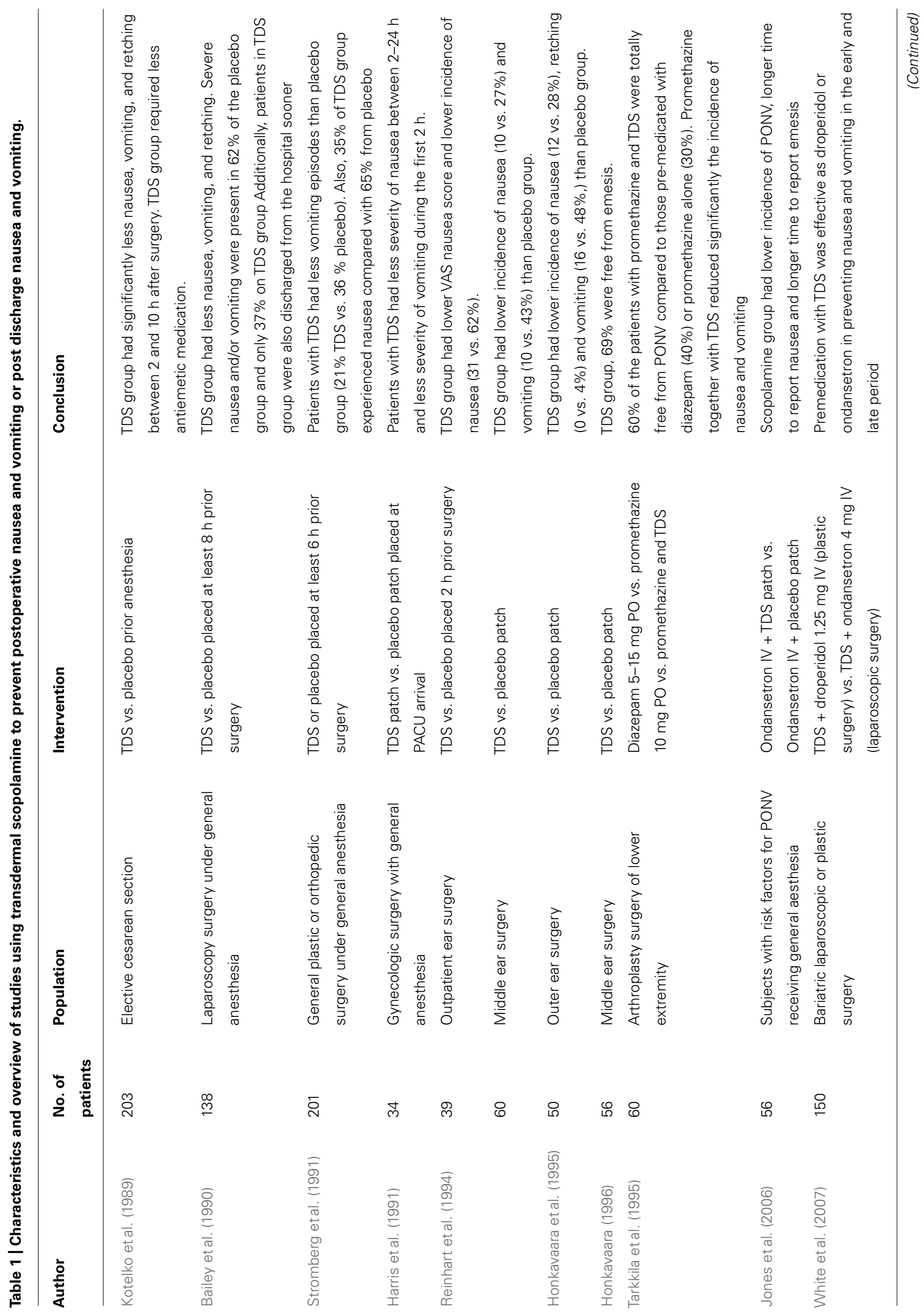




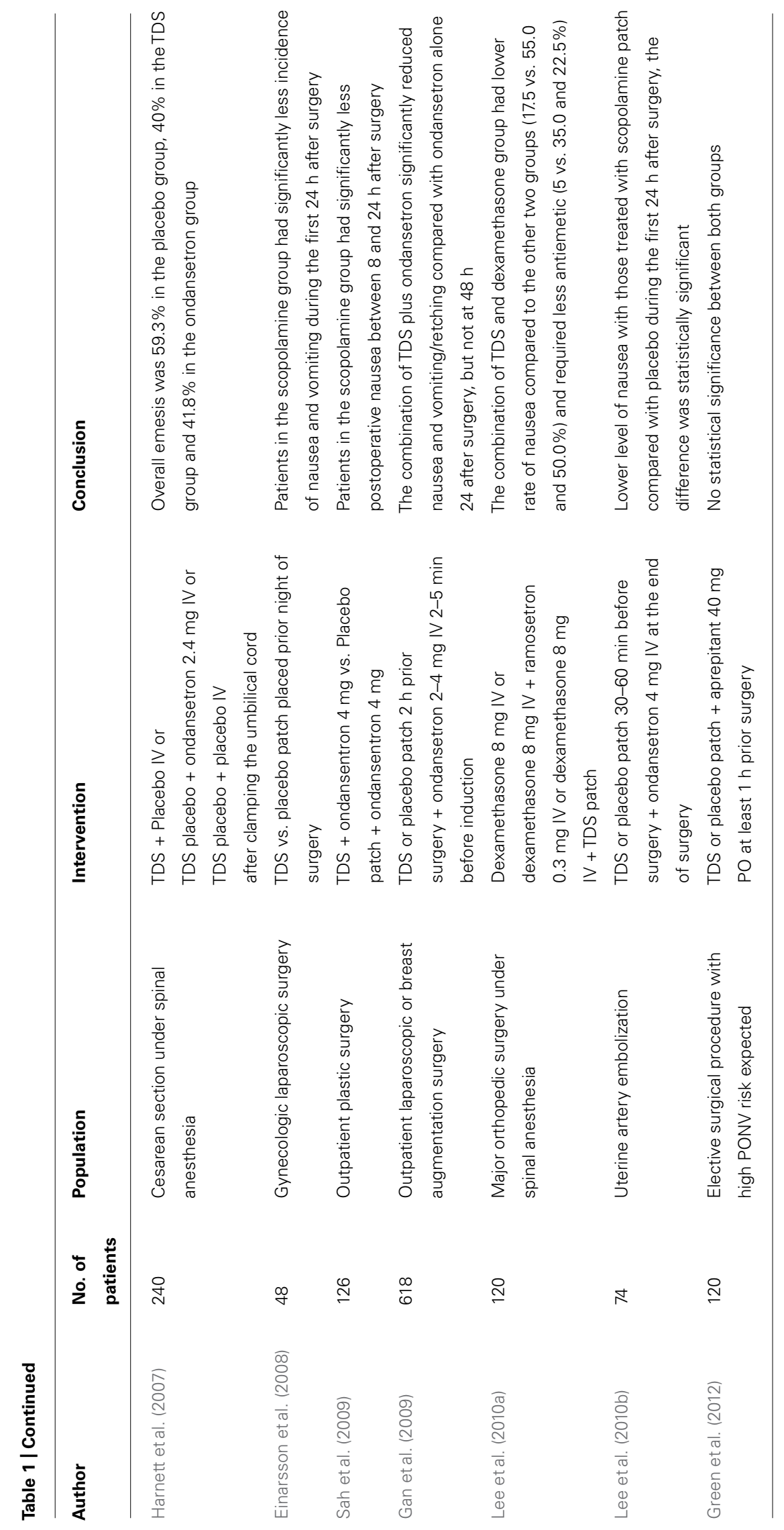


nausea after UAE was low; there was a lower level of nausea in patients treated with TDS compared to the group that did not receive ondansetron during the first $24 \mathrm{~h}$ after embolization. Adverse events were more common with the TDS group, with two patients experiencing episodes of profound disorientation and $71 \%$ reporting substantial dry mouth. These results suggest that although the TDS provides moderate reduction of nausea, its use is associated with infrequent but notable episodes of patient disorientation.Therefore, the decision whether to use or not a TDS should be based on careful consideration of the potential benefits vs. the possibility of unwanted side effects for a given practice setting (Lee et al., 2010b). Green et al. (2012) compared aprepitant alone vs. aprepitant with scopolamine in patients undergoing elective surgical procedures and with two or more Apfel four-point risk factors. The study showed no difference in complete response (63\% vs. $57 \%, P=0.57$ ) between both groups In addition, there was no difference between the numbers of patients who did not report any PONV those who used a rescue medication (Green et al., 2012). Clinical trials with TDS have consistently demonstrated its safety and efficacy as an antiemetic in many medical situations that frequently result in severe nausea and vomiting. In a meta-analysis study, Apfel et al. (2010) revealed a reduced risk of severe nausea and vomiting in patients receiving TDS compared to patients receiving placebo. TDS was shown to reduce the risk of postoperative nausea (relative risk, $R R=0.77$; 95\% CI, 0.61-0.98; $P=0.03$ ) The most prevalent side effect registered at $24-48 \mathrm{~h}$ after surgery was the occurrence of visual disturbances $(R R=3.35 ; 95 \%$ CI, 1.78-6.32) (Apfel et al., 2010).

\section{SAFETY AND TOXICITY}

Studies have consistently shown that the TDS is safe and well tolerated initially in patients treated for motion sickness. Later studies showed its efficacy for prophylaxis of PONV in patients undergoing various surgical procedures, including abdominal, and orthopedic. The most common side effects described throughout the different studies were dry mouth $(\sim 29 \%)$, dizziness (less than $8 \%$ ), blurred vision (less than $4 \%$ ), and disorientation (less than 1\%; Package Insert, 2006). TDS is not recommended for administration in children and should be used with special caution in patients with pyloric obstruction, intestinal obstruction, impaired liver, and kidney function, obstructive urinary dysfunction, and glaucoma. The patch is contraindicated in patients hypersensitive to scopolamine and other belladonna alkaloids, as well as plaster allergies (Renner et al., 2005; Package Insert, 2006). In pregnant women, scopolamine should be administered only when potential benefits will overweight the risks to the fetus. Currently, there are not enough data to prove Scopolamine's safety in pregnant or lactating mothers (Ayromlooi et al., 1980; Evens and Leopold, 1980; Briggs et al., 1994), although the drug is considered compatible with nursing and is not considered teratogenic. Scopolamine toxicity has been described in a newborn with symptoms such as tachycardia, fever, and lethargy (Renner et al., 2005).

\section{DISCUSSION}

Despite the recognition of PONV as a contributing factor to postoperative morbidity, it still remains an actual medical problem necessitating a search for newer therapies. Current PONV risk stratification tools are helpful in providing a semi-quantitative risk assessment of PONV. Nevertheless, newer approaches and screening methods are to be developed to better reflect the patients' and clinicians' perception of PONV, provide a reliable means of highrisk patient selection, and reduce the overall impact of this complication on perioperative outcome. PONV pharmacotherapy and prophylaxis are based on monotherapy using a single antiemetic or combinations of several drugs. Multiple clinical trials have proven the safety and clinical efficacy of the TDS in treatment of PONV in various patient groups when used as a single drug or in combination with other drugs. TDS may be an effective method of PONV prophylaxis when applied within $2 \mathrm{~h}$ prior to surgery and anesthesia (Kotelko et al., 1989; Reinhart et al., 1994; Jones et al., 2006; White et al., 2007; Gan et al., 2009; Sah et al., 2009; Lee et al., 2010a,b; Green etal., 2012). This can be explained by the fast release and absorption of the loading dose in the inner layer of the patch.

The most recent consensus guidelines for the management of PONV address the issue of providing antiemetic therapy in those patients in whom prophylaxis has failed. They recommend that an antiemetic from a different pharmacologic class than the drug(s) administered for prophylaxis be given (Gan et al., 2014). They cite that the 5-HT3 antagonist class as being the only class that have been extensively studied for the treatment of existing PONV, and that this class should be administered prefererentially if not already given for prophylaxis. The guidelines also list alternative treatments to treat established PONV including dexamethasone, droperidol, or promethazine, and low dose propofol (Gan et al., 2014). If TDS is selected as a first-line agent for PONV prophylaxis medication, then this would leave more of the other drug classes available to treat established PONV if prophylaxis happens to fail. Due to the longer duration and pharmacokinetic profile, TDS may also be beneficial for prevention of PDNV, although further studies need to be performed to study this effect.

In conclusion, an effective management of PONV mandates understanding the pathophysiological mechanisms of PONV development and pharmacologic profiles of the applied medications, as well as their interaction with anesthetics, and other drugs used during the perioperative period. Effective reduction of the frequency and severity of PONV in various patient groups can be achieved with judicious use mono- or combination pharmacotherapy or non-pharmacological methods. Current scientific evidence indicates that TDS may be effectively used for prophylaxis and therapy of PONV.

\section{ACKNOWLEDGMENTS}

The authors would like to thank, Ala-Eddin Sagar, for his valuable contribution to the research and preparations of this manuscript and Keri Hudec for her editorial assistance.

\section{REFERENCES}

Apfel, C. C., Laara, E., Koivuranta, M., Greim, C. A., and Roewer, N. (1999). A simplified risk scores for predicting postoperative nausea and vomiting: conclusions from cross-validations between two centers. Anesthesiology 91, 693-700. doi: 10.1097/00000542-199909000-00022 
Apfel, C. C., Zhang, K., George, E., Shi, S., Jalota, L., Hornuss, C., et al. (2010). Transdermal scopolamine for the prevention of postoperative nausea and vomiting: a systematic review and meta-analysis. Clin. Ther. 32, 1987-2002. doi: 10.1016/j.clinthera.2010.11.014

Ayromlooi, J., Tobias, M., and Berg, P. (1980). The effects of scopolamine and ancillary analgesics upon the fetal heart rate recording. J. Reprod. Med. 25, 323 326.

Bailey, P. L., Streisand, J. B., Pace, N. L., Bubbers, S. J., East, K. A., Mulder, S., et al. (1990). Transdermal scopolamine reduces nausea and vomiting after outpatient laparoscopy. Anesthesiology 72, 977-980. doi: 10.1097/00000542-19900600000005

Briggs, G. G., Freeman, R. K., and Yaffe, S. J. (1994). Drugs in Pregnancy and Lactation: a Reference Guide to Fetal and Neonatal Risk, 4th Edn, Williams and Wilkins: Baltimore.

Dahl, E., Offer-Ohlsen, D., and Lillevold, P. E. (1984). Transdermal scopolamine, oral meclizine, and placebo in motion sickness. Clin. Pharmacol. Ther. 36, 116-120. doi: $10.1038 /$ clpt.1984.148

Einarsson, J. I., Audbergsson, B. O., and Thorsteinsson, A. (2008). Scopolamine for prevention of postoperative nausea in gynecologic laparoscopy, a randomized trial. J. Minim. Invasive Gynecol. 15, 26-31. doi: 10.1016/j.jmig.2007. 08.616

Evens, R. P., and Leopold, J. C. (1980). Scopolamine toxicity in newborn. Pediatrics $66,329-330$

Fabling, J. M., Gan, T. G., El-Moalem, H. E., Warner, D. S., and Borel, C. O. (2000) A randomized, double-blinded comparison of ondansetron, droperidol, and placebo for prevention of postoperative nausea and vomiting after supratentorial craniotomy. Anesth. Analg. 91, 358-361.

Feng, P. H., Chu, K. S., Lu, I. C., Shieh, J. P., Tzeng, J. I., Ho, S. T., et al. (2009) Haloperidol plus ondansetron prevents postoperative nausea and vomiting in patients undergoing laparoscopic cholecystectomy. Acta Anaesthesiol. 47, 3-9. doi: 10.1016/S1875-4597(09)60013-8

Gan, T. J., Diemunsch, P., Habib, A. S., Kovac, A., Kranke, P., Meyer, T. A., et al. (2014). Consensus guidelines for the management of postoperative nausea and vomiting. Anesth. Analg. 118, 85-113. doi: 10.1213/ANE.00000000000 00002

Gan, T. J., and Habib, A. S. (2003). Pharmacotherapy of postoperative nausea and vomiting. Expert Opin. Pharmacother. 4, 1-16.

Gan, T. J., Sinha, A. C., Kovac, A. L., Jones, R. K., Cohen, S. A., Battikha, J. P. et al. (2009). A randomized, double-blind, multicenter trial comparing transdermal scopolamine plus ondansetron to ondansetron alone for the prevention of postoperative nausea and vomiting in the outpatient setting. Anesth. Analg. 108, 1498-1504. doi: 10.1213/ane.0b013e31819e431f

Graybiel, A. (1979). Prevention and treatment of space sickness in shuttle-orbiter missions. Aviat. Space Environ. Med. 50, 171-176.

Graybiel, A., Cramer, D. B., and Wood, C. D. (1981). Experimental motion sickness: efficacy of transdermal scopolamine plus ephedrine. Aviat. Space Environ. Med. 52, 337-339.

Graybiel, A., Cramer, D. B., and Wood, C. D. (1982). Antimotion-sickness efficacy of scopolamine 12 and 72 hours after transdermal administration. Aviat. Space Environ. Med. 53, 770-772.

Green, M. S., Green, P., Malayaman, S. N., Hepler, M., Neubert, L. J., and Horrow, J. C. (2012). Randomized, double-blind comparison of oral aprepitant alone compared with aprepitant and transdermal scopolamine for prevention of postoperative nausea and vomiting. $\mathrm{Br}$. J. Anaesth. 109, 716-722. doi: 10.1093/bja/aes233

Harris, S. N., Sevarino, F. B., Sinatra, R. S., Preble, L., O'Connor, T. Z., and Silverman, D. G. (1991). Nausea prophylaxis using transdermal scopolamine in the setting of patient-controlled analgesia. Obstet. Gynecol. 78, 673-677.

Harnett, M., O’Rourke, N., Walsh, M., Carabuena, J. M., and Segal, S. (2007). Transdermal scopolamine for prevention of intrathecal morphine-induced nausea and vomiting after cesarean delivery. Anesth. Analg. 105, 764-769. doi: 10.1213/01.ane.0000277494.30502.db

Honkavaara, P. (1996). Effect of transdermal hyoscine on nausea and vomiting during and after middle ear surgery under local anaesthesia. Br. J. Anaesth. 76, 49-53. doi: 10.1093/bja/76.1.49

Honkavaara, P., Saarnivaara, L., and Klemola, U. M. (1995). Effect of transdermal hyoscine on nausea and vomiting after surgical correction of prominent ears under general anaesthesia. Br. J. Anaesth. 74, 647-650. doi: 10.1093/bja/74.6.647
Jones, S., Strobl, R., Crosby, D., Burkard, J. F., Maye, J., and Pellegrini, J. E. (2006) The effect of transdermal scopolamine on the incidence and severity of postoperative nausea and vomiting in a group of high-risk patients given prophylactic intravenous. AANA J. 74, 127-132.

Kotelko, D. M., Rottman, R. L., Wright, W. C., Stone, J. J., Yamshiro, A. Y., and Rosenblatt, R. M. (1989). Transdermal scopolamine decreases nausea and vomiting following cesarean section in patients receiving epidural morphine. Anesthesiology 71, 675-678. doi: 10.1097/00000542-198911000-00009

Lee, H. K., Lee, J. H., Chon, S. S., Ahn, E. K., and Jnag, Y. H. (2010a). The effect of transdermal scopolamine plus intravenous dexamethasone for the prevention of postoperative nausea and vomiting in patients with epidural pca after major orthopedic surgery. Korean J. Anesthesiol. 58, 50-55. doi: 10.4097/kjae.2010.58.1.50

Lee, J. S., Costantino, M., McCullough, M. F., Lee, J. B., Jones, M. M., Carter, E. A., et al. (2010b). Transdermal scopolamine patch with ondansetron for the control of nausea after uterine artery embolization compared with ondansetron alone: results of a randomized placebo-controlled trial. J. Vasc. Interv. Radiol. 21, 1018-1023. doi: 10.1016/j.jvir.2010.02.035

Lipp, A., and Kaliappan, A. (2007). Focus on quality: managing pain and PONV in day surgery. Curr. Anaesth. Crit. Care 18, 200-207. doi: 10.1016/j.cacc.2007.07.013

Nachum, Z., Shupak, A., and Gordon, C. (2006). Transdermal scopolamine for prevention of motion sickness: clinical pharmacokinetics and therapeutic applications. Clin. Pharmacokinet. 45, 543-566. doi: 10.2165/00003088-20064506000001

Package Insert. (2006). Parsippany, NJ: Novartis Consumer Health, Inc. ALZA Corporation.

Pergolizzi, J. V. Jr., Philip, B. K., Leslie, J. B., Taylor, R. Jr., and Raffa, R. B. (2012). Perspective on transdermal scopolamine for the treatment of postoperative nausea and vomiting. J. Clin. Anesth. 24, 334-345, doi: 10.1016/j.jclinane.2011. 07.019

Pergolizzi, J. V., Raffa, R., and Taylor, R. (2011). Prophylaxis of postoperative nausea and vomiting in adolescent patients: a review with emphasis on combination of fixed-dose ondansetron and transdermal scopolamine. J. Drug Deliv. 2011, 7. doi: $10.1155 / 2011 / 426813$

Reinhart, D. J., Klein, K. W., and Schroff, E. (1994). Transdermal scopolamine for the reduction of postoperative nausea in outpatient ear surgery: a double blind, randomized study. Anesth. Analg. 79, 281-284. doi: 10.1213/00000539199408000-00013

Renner, U. F., Oertel, R., and Kirch, W. (2005). Pharmacokinetics and pharmacodynamics in clinical use of scopolamine. Ther. Drug Monit. 27, 655-665. doi: 10.1097/01.ftd.0000168293.48226.57

Sah, N., Ramesh, V., Kaul, B., Dalby, P., Shestak, K., and Vallejo, M. C. (2009). Transdermal scopolamine patch in addition to ondansetron for postoperative nausea and vomiting prophylaxis in patients undergoing ambulatory cosmetic surgery. J. Clin. Anesth. 21, 249-252. doi: 10.1016/j.jclinane.2008. 08.017

Shojaku, H., Watanabe, Y., and Ito, M. (1993). Effect of transdermally administered scopolamine on the vestibular system in humans. Acta Otolaryngol. Suppl. 504, 41-45. doi: 10.3109/00016489309128120

Sood, M., Kaushal, S., and Chopra, S. C. (2007). Aprepitant in PONV. J. Anesth Clin. Pharmacol. 23, 395-398.

Stromberg, B. V., Reines, D. H., and Ackerly, J. (1991). Transderm scopolamine for the control of perioperative nausea. Am. Surg. 57, 712-715.

Tarkkila, P., Torn, K., Tuominen, M., and Lindgren, L. (1995). Premedication with promethazine and transdermal scopolamine reduces the incidence of nausea and vomiting after intrathecal morphine. Acta Anaesthesiol. Scand. 39, 983-986. doi: 10.1111/j.1399-6576.1995.tb04210.x

White, P. F., Tang, J., Song, D., Coleman, J. E., Wender, R. H., Ogunnaike, B., et al. (2007). Transdermal scopolamine: an alternative to ondansetron and droperidol for the prevention of postoperative and postdischarged emetic symptoms. Anesth. Analg. 104, 92-96. doi: 10.1213/01.ane.0000250364. 91567.72

Conflict of Interest Statement: Sergio D. Bergese has a consulting agreement with Baxter Healthcare Corporation, active since 2010. TDS is licensed by Baxter Healthcare Corporation. Joseph V. Pergolizzi is a consult for Baxter Healthcare Corporation, Eisai Inc., Hospira and GlaxosmithKline. 
Received: 27 January 2014; accepted: 13 March 2014; published online: 09 April 2014. Citation: Antor MA, Uribe AA, Erminy-Falcon N, Werner JG, Candiotti KA, Pergolizzi $J V$ and Bergese SD (2014) The effect of transdermal scopolamine for the prevention of postoperative nausea and vomiting. Front. Pharmacol. 5:55. doi: 10.3389/fphar. 2014.00055

This article was submitted to Cardiovascular and Smooth Muscle Pharmacology, a section of the journal Frontiers in Pharmacology.
Copyright (C) 2014 Antor, Uribe, Erminy-Falcon, Werner, Candiotti, Pergolizzi and Bergese. This is an open-access article distributed under the terms of the Creative Commons Attribution License (CC BY). The use, distribution or reproduction in other forums is permitted, provided the original author(s) or licensor are credited and that the original publication in this journal is cited, in accordance with accepted academic practice. No use, distribution or reproduction is permitted which does not comply with these terms. 